\title{
Variabilidade mensal e sazonal da temperatura do solo em diferentes condições de cobertura e de profundidades na região de Tangará da Serra, Mato Grosso
}

\section{Monthly and seasonal variability of soil temperature at different ground cover and depth conditions in Tangará da Serra region, Mato Grosso}

\author{
Karolina Ascari Souza de OLIVEIRA ${ }^{1}$; Rivanildo DALLACORT ${ }^{2}$; João Danilo BARBIERI ${ }^{3}$; \\ Diego Fernando DANIEL ${ }^{4}$; Rafael Cesar TIEPPO ${ }^{5}$; Silmara Bispo dos SANTOS ${ }^{6}$
}

\begin{abstract}
${ }^{1}$ Mestre em Ambiente e Sistemas de Produção Agrícola, Universidade do Estado de Mato Grosso -UNEMAT, MT-358, 7 Jardim Aeroporto, Tangará da Serra - MT, 78300-000, e-mail: karolinaascari@gmail.com

${ }^{2}$ Professor do programa de pós graduação em Ambiente e Sistema de Produção Agrícola, Universidade do Estado de Mato Grosso - UNEMAT, e-mail: rivanildo@unemat.br

${ }^{3}$ Autor para correspondência. Doutorando em Agronomia, Universidade Estadual de Maringá - UEM, Av. Colombo, 5790 - Jd. Universitário, Maringá - PR, 87020-900, e-mail: jd.barbieri@hotmail.com

${ }^{4}$ Graduando em Agronomia, Universidade do Estado de Mato Grosso - UNEMAT, e-mail: diegodanielmt@gmail.com

${ }^{5}$ Professor Adjunto do departamento de Agronomia, Universidade do Estado de Mato Grosso - UNEMAT, e-mail: rafaelt@unemat.br

${ }^{6}$ Professora Adjunta da Universidade Federal de Mato Grosso - UFMT, Instituto de Ciências Agrárias e Tecnológicas/Engenharia Mecânica, Avenida dos Estudantes, 5005 - Vila Aurora I, Rondonópolis - MT, 78735-901, , E-mail: syllmara@yahoo.com.br
\end{abstract}

Recebido em: 13-02-2019; Aceito em: 22-04-2019

\section{Resumo}

O objetivo deste estudo foi comparar as respostas térmicas em dois tratamentos experimentais (solo descoberto e solo cultivado com grama) durante o período seco e chuvoso, e nas estações do ano (primavera, verão, outono e inverno) para a região de Tangará da Serra - MT. O monitoramento das variações na temperatura do solo, nos sítios de avaliação, foi realizado continuamente, do período de abril de 2014 a abril de 2015. Avaliou-se a temperatura do solo em clima tropical úmido megatérmico (AW), em um Latossolo Vermelho distroférrico muito argiloso, na região sudoeste do Estado de Mato Grosso. Foram instalados sensores Termopar tipo K, nas profundidades de 5; 10; 20 e $40 \mathrm{~cm}$, conectados a um datalogger. Os resultados apresentaram alterações significativas entre os diferentes tratamentos e meses estudados. As médias de temperatura de solo horária durante a estação chuvosa foram superiores às registradas durante a estação seca, porém as amplitudes térmicas, durante o período seco, foram superiores às do período chuvoso, destacando-se o papel fundamental da cobertura no solo, na redução da amplitude térmica e da umidade na condução de calor entre as camadas. As maiores oscilações na temperatura e na amplitude térmica, em ambos os tratamentos e meses estudados, foram observadas aos $5 \mathrm{~cm}$, seguidas das demais camadas avaliadas. $\mathrm{Na}$ análise de estações do ano, verificou-se que, durante o inverno, as temperaturas são inferiores às ocorridas no verão, na primavera e no outono, porém a amplitude térmica registrada é superior durante o inverno em relação às outras estações do ano.

Palavras-chave adicionais: amplitude térmica; condutividade; termopar; Zoysia japonica Steud.

\begin{abstract}
The objective of this study was to compare the thermal responses in two experimental treatments (uncovered soil and soil cultivated with grass) during the dry and rainy season and in the seasons (spring, summer, autumn and winter) in Tangará da Serra - MT. The monitoring of variations in soil temperature at the assessment sites was carried out continuously from April 2014 to April 2015. The soil temperature was measured in tropical megatérmico humid climate (AW), in a very clayey Dystroferric Red Latosol in the southwestern region of the State of Mato Grosso. Thermocouple type K sensors were installed at depths of 5, 10, 20 and $40 \mathrm{~cm}$, connected to a datalogger. The results showed significant changes between the different treatments and months studied. The average hourly soil temperatures during the rainy season were higher than those recorded during the dry season, but the thermal amplitudes during the dry period were higher than those of the rainy season, highlighting the fundamental role of soil cover in reducing the amplitude thermal and humidity in the conduction of heat between the layers. The highest oscillations in temperature and thermal amplitude in both treatments and months studied were observed at $5 \mathrm{~cm}$, followed by the other layers evaluated. In the analysis of seasons, it was verified that during winter the temperatures are lower than those occurring in summer, spring and autumn, however, the recorded thermal amplitude is higher during the winter compared to other seasons of the year.
\end{abstract}

Additional keywords: conductivity; temperature range; thermocouple; Zoysia japonica Steud. 


\section{Introdução}

O solo é um dos principais fatores responsáveis pela produção agrícola, seja pelo papel de suporte às plantas, seja pelo fornecimento de condições indispensáveis ao seu desenvolvimento, regulando a disponibilidade de água, nutrientes e calor (Silveira \& Freitas, 2007). A temperatura do solo é influenciada pela intensidade de radiação solar incidente na superfície do solo, bem como pelas suas propriedades térmicas, exercendo efeito significativo sobre o crescimento e o desenvolvimento das plantas (Carneiro et al., 2013).

Poucos estudos têm sido realizados envolvendo a variável temperatura do solo, embora seja uma observação padrão em postos e em estações meteorológicas. No entanto, este é um dos principais fatores limitantes para o crescimento e o desenvolvimento das plantas, visto que a semente não germina até que o solo alcance uma temperatura ideal, bem como na atividade funcional do sistema radicular, na absorção de água e de nutrientes do solo, podendo então controlar o desenvolvimento e a distribuição das plantas no solo (Hillel, 2004).

As características físicas, químicas e biológicas do solo, bem como a variação temporal da transferência de calor e de água entre as camadas e a atmosfera são fatores que determinam as flutuações nos perfis de temperatura em determinado local (Lima et al., 2013). Além disso, estas sofrem influência do clima da região, da cobertura presente no solo e da manutenção dos restos culturais na superfície do solo, fatores responsáveis pelas alterações nas transferências de calor e de água na atmosfera (Resende et al., 2005).

Sendo assim, conhecer a temperatura do solo proporciona melhor entendimento sobre as interações solo-planta-atmosfera, dado que o calor armazenado próximo da superfície do solo tem grande efeito na evaporação (Dalmago et al., 2010). Dessa forma, estudos nesta área podem fornecer bases para o desenvolvimento de técnicas de cultivo mais adequadas, inclusive ecologicamente, para os diversos tipos de clima.

A presença de cobertura sobre a superfície do solo protege-o contra o aquecimento excessivo e a perda de água por evaporação, mantendo o solo mais úmido e reduzindo as oscilações de temperatura e de umidade do solo (Knies, 2010, Ribas et al., 2015). Segundo Oliveira et al. (2005), o solo sem cobertura apresenta a maior amplitude de variação da temperatura ambiente acima da superfície, registrando os menores valores de umidade e os maiores de temperatura. Do mesmo modo, a presença de plantas interfere no processo de evaporação da água, pois com o crescimento da área foliar, ocorre um aumento da interceptação da radiação solar incidente, expandindo o sombreamento do solo e reduzindo a quantidade de energia que chega a ele (Dalmago et al., 2010, Bergamaschi \& Matzenauer, 2014).

A aquisição de dados sobre a resposta da temperatura, em solos ocorrentes em clima tropical úmido, auxilia no entendimento das relações soloplanta nessas regiões e oferece subsídios para o estudo de técnicas de cultivo adequadas a esse tipo de clima (Matteucci \& Lobato, 2004). Os solos do tipo Latossolo Vermelho são alguns dos mais expressivos em termo de ocorrência no Estado de Mato Grosso, ocorrendo em $23,63 \%$ das áreas do estado, principalmente no Planalto dos Parecis, sendo coberto tanto por áreas de cerrado como por Floresta (SEPLAN, 2003). Desta maneira, além do clima, o conhecimento de como a temperatura varia em diferentes profundidades, nos tipos de solos existentes em determinada região, contribui para o aprofundamento do conhecimento do tema investigado.

Diante da importância da temperatura do solo, o presente trabalho teve como objetivo comparar as respostas térmicas em dois tratamentos experimentais (solo descoberto e solo cultivado com grama), durante as estações seca e chuvosa, e as estações do ano (primavera, verão, outono e inverno), para a região de Tangará da Serra, sudoeste do Estado de Mato Grosso.

\section{Material e métodos}

O experimento foi conduzido na área experimental pertencente ao Laboratório de Agrometeorologia do Centro de Pesquisa e Desenvolvimento Agroambiental (CEPEDA) da Universidade do Estado de Mato Grosso - UNEMAT, localizada no município de Tangará da Serra - MT, região sudoeste do estado, nas coordenadas geográficas de latitude $14^{\circ} 37^{\prime} 10^{\prime \prime} \mathrm{S}$, longitude $57^{\circ} 29^{\prime} 09^{\prime \prime} \mathrm{O}$ e altitude de 440 metros. O clima da região é o tropical úmido megatérmico (AW), com valores médios anuais de temperatura, precipitação e umidade relativa do ar de $24,4{ }^{\circ} \mathrm{C}, 1.830 \mathrm{~mm}$ e $70-80 \%$, respectivamente (Dallacort et al., 2010, Dallacort et al., 2011). O solo é do tipo Latossolo Vermelho distroférrico muito argiloso, com características físicas de areia $\left(260,80 \mathrm{~g} \mathrm{~kg}^{-1}\right)$, silte $\left(135,20 \mathrm{~g} \mathrm{~kg}^{-1}\right) \mathrm{e}$ argila $\left(604,00 \mathrm{~g} \mathrm{~kg}^{-1}\right)$, segundo análise de solo e como descrito em Dalchiavon et al. (2010) e Embrapa (2013).

O experimento foi composto por dois tratamentos, constituídos por solo cultivado com grama (T1), utilizando-se da gramínea Zoysia japonica Steud, conhecida comercialmente como Grama-Esmeralda, cujo transplantio foi realizado no dia 22 de março de 2014, com tapetes de grama, de forma a cobrir toda a área de $25 \mathrm{~m}^{2}$. No início da avaliação, a grama já se encontrava em pleno desenvolvimento, sempre mantida a $10 \mathrm{~cm}$ de altura. $\mathrm{O}$ tratamento (T2) constituído de solo descoberto, também com dimensão de $25 \mathrm{~m}^{2}$, sempre mantido sem presença de qualquer planta, apresentando o experimento área total de $50 \mathrm{~m}^{2}$.

Em cada tratamento, foram abertas trincheiras com $50 \mathrm{~cm}$ de profundidade, onde se instalaram sensores de temperatura do solo, do tipo Termopar tipo K, estes constituídos por cobre e constantan, encapsulados por alumínio e vedados com resina e fita de auto- 
fusão, colocados nas profundidades de 5; 10; 20 e 40 $\mathrm{cm}$. Os sensores foram conectados a uma placa multiplexadora vinculada a um datalogger modelo CR1000 da Campbell Scientific, com armazenamento dos dados em intervalos de 10 minutos.

As observações de temperatura do solo realizadas durante o experimento, nos dois tratamentos e nas diferentes profundidades, foram monitoradas durante 17 meses, no período de abril de 2014 a agosto de 2015. Concomitantemente, foram monitoradas as variáveis meteorológicas (temperatura do ar, precipitação e radiação), com dados meteorológicos obtidos de uma estação automática, pertencente ao laboratório de Agrometeorologia, localizada no campo experimental da Universidade do Estado de Mato Grosso (UNEMAT). Posteriormente, realizou-se a análise da resposta horária das temperaturas máxima, média e mínima do solo, em ambos os tratamentos estudados.

Para a análise da variação da temperatura do solo durante as estações seca e chuvosa, os dados coletados foram separados seguindo critério proposto por Dallacort et al. (2010), determinando que a região de Tangará da Serra - MT, possui duas estações definidas; uma seca, de maio a setembro, e outra chuvosa, de outubro a abril. Os dados foram separados, de forma que os meses de maio a setembro de 2014 corresponderam à estação seca, os meses de outubro a dezembro de 2014 e janeiro a abril de 2015 à estação chuvosa, e de maio a agosto de 2015 à estação seca.

Além da análise sazonal, realizou-se também a estacional, separando-se os dados em primavera (setembro a dezembro - 2014), verão (dezembro 2014 a março - 2015), outono (março a junho - 2015) e inverno (junho a setembro - 2014), analisando-se a variabilidade horária dentro de cada estação, nos tratamentos estudados, realizando-se uma média horária dos dias pertencentes a cada estação do ano, comparando, assim, a resposta da temperatura do solo entre as estações. As análises dos dados foram organizadas em planilhas do software Microsoft Excel ${ }^{\circledR}$, onde posteriormente foram gerados gráficos.

Por fim, verificou-se a variação entre a temperatura do solo e a temperatura do ar, para os períodos diurno e noturno, durante as estações chuvosa e seca, nos diferentes tratamentos e profundidades, sendo realizada a diferença entre a temperatura do solo e a temperatura do ar no mesmo momento, ou seja, temperatura do solo menos a temperatura do ar. Os valores da diferença da temperatura foram comparados utilizando-se o software $R$ Studio ( $R$ Development Core Team, 2017).

\section{Resultados e discussão}

\section{Variabilidade mensal da temperatura do solo}

Os valores médios mensais de temperatura do solo, nas diferentes profundidades e condições de cobertura de solo estudadas, bem como a temperatura média do ar e o acumulado de precipitação durante o período experimental, são apresentados na Figura 1. Os valores de temperatura do solo mostraram-se maiores nos meses chuvosos devido à presença de umidade no solo, pois a presença de água afeta o fluxo de calor do solo, ou seja, a presença de umidade no solo modifica os valores de temperatura do solo, aumentando em períodos que ocorrem maiores precipitações (Carneiro et al., 2013).

No solo cultivado com grama, as camadas de 10; 20 e $40 \mathrm{~cm}$ apresentaram valores médios superiores aos observados na camada superficial (Figura 1A). Segundo Mateucci \& Lobato (2004), o aumento da temperatura nas camadas de 10; 20 e $40 \mathrm{~cm}$ ocorre devido ao acúmulo de calor no solo desde o dia anterior. Segundo Bezerra et al. (2016) as variações na superfície do solo são superiores às do seu interior, em decorrência da absorção, da perda de energia e da baixa velocidade de propagação nas camadas inferiores.

No solo descoberto, a temperatura na superfície foi superior às demais camadas nos meses de abril, agosto e setembro de 2014 e agosto de 2015, sendo esta resposta mais perceptível nos meses de agosto e setembro de 2014 e agosto de 2015. Nos demais meses, a variação da temperatura, nas diferentes camadas, não seguiu um padrão definido, sendo pouco observadas variações nas diferentes camadas. Entretanto, sua variação acompanhou 0 curso anual da temperatura média do ar (Figura 1B). Tal fato ressalta a influência da temperatura do ar sobre a dinâmica da temperatura no perfil do solo.

Aos $5 \mathrm{~cm}$ de profundidade, o solo descoberto apresentou médias superiores às do solo com grama, exceto para os meses de março, abril e maio de 2015. A média anual de temperatura aos $5 \mathrm{~cm}$, durante 0 período estudado, foi de $28,1^{\circ} \mathrm{C}$ no solo sem cobertura e $26,1^{\circ} \mathrm{C}$ no solo com grama; assim, a cobertura na superfície do solo provocou a redução de $2^{\circ} \mathrm{C}$. Resultados próximos foram descritos por Menezes et al. (1973), que ao analisar valores de temperaturas coletados no Estado do Rio de Janeiro, nas profundidades de $5 ; 10 ; 15 ; 20 ; 30 ; 40 ; 50$ e 100 cm, obtiveram médias de $26,8^{\circ} \mathrm{C}$ em solo capinado, $25,9^{\circ} \mathrm{C}$ em solo gramado e $24,8^{\circ} \mathrm{C}$ em solo com restos culturais de gramíneas com espessura de $5 \mathrm{~cm}$.

As maiores médias de temperatura, no solo coberto com grama, foram registradas no mês de março de 2015, com 28,6; 28,7; 28,7 e $28,7^{\circ} \mathrm{C}$, para as camadas de $5 ; 10 ; 20$ e $40 \mathrm{~cm}$, respectivamente. As observações em solo descoberto, entre os meses de setembro de 2014 e agosto de 2015, foi onde se verificaram as maiores temperaturas em todas as camadas, permanecendo com médias acima de $30^{\circ} \mathrm{C}$, exceto na camada de $40 \mathrm{~cm}\left(29,9^{\circ} \mathrm{C}\right)$. As menores médias de temperatura mensal foram registradas durante o mês de julho de 2014, com temperaturas abaixo de $26^{\circ} \mathrm{C}$, em ambos os tratamentos, sendo este o mês cuja temperatura do ar foi de $22,3^{\circ} \mathrm{C}$, a menor média mensal durante o período estudado. 

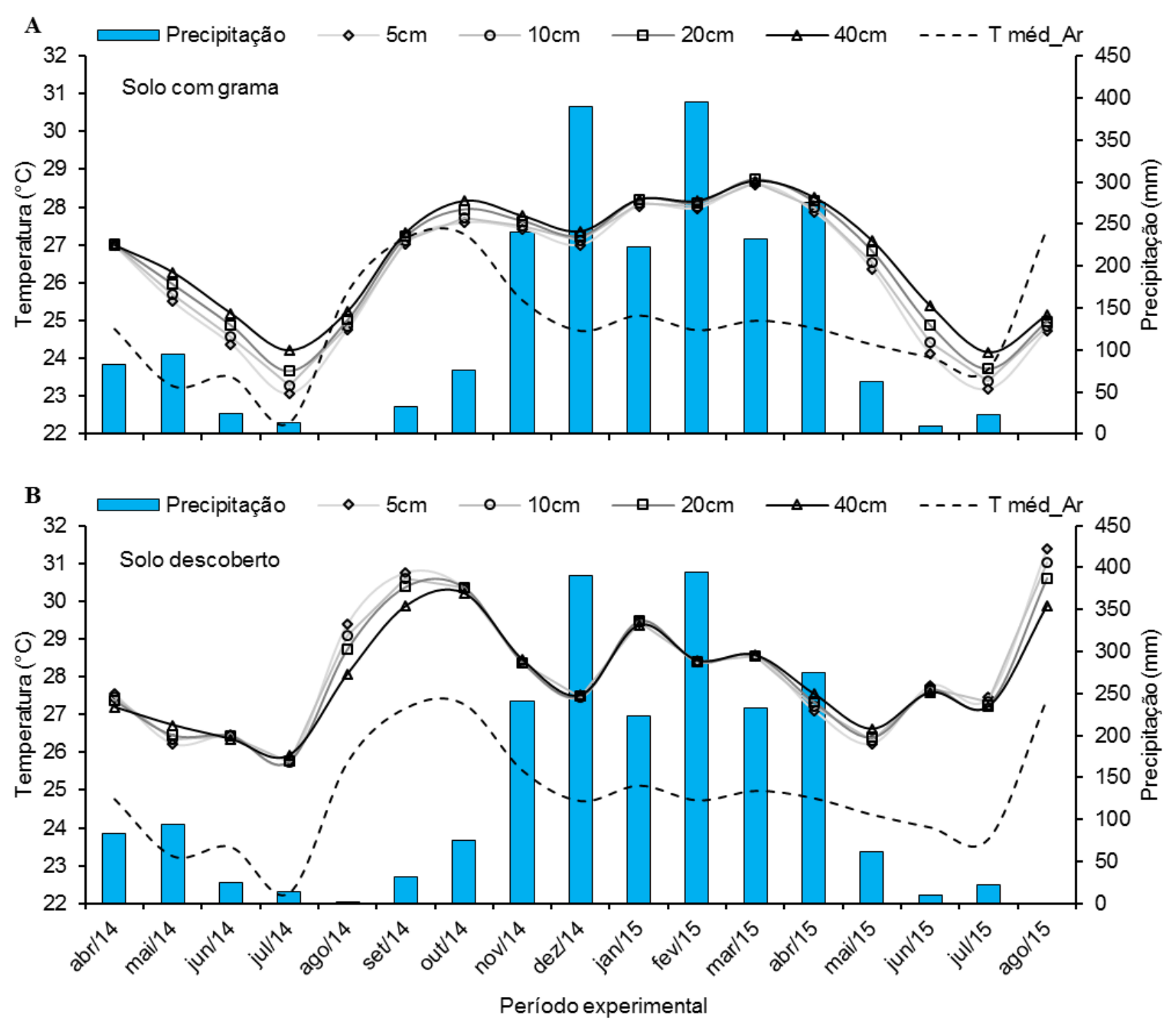

Figura 1 - Variação da temperatura média do ar e do solo em diferentes profundidades para solo com grama e solo descoberto, precipitação acumulada para os meses decorrentes do experimento. Variation of mean air and soil temperature at different depths for soil with grass and uncovered soil, cumulative rainfall for the months resulting from the experiment.

Ao analisar o efeito da grama sob a temperatura média mensal, os valores foram inferiores aos do solo descoberto, apresentando diferenças de $2^{\circ} \mathrm{C}$, $1,8^{\circ} \mathrm{C}, 1,4^{\circ} \mathrm{C}$ e $1,3^{\circ} \mathrm{C}$, nas camadas de $5 ; 10 ; 20$ e $40 \mathrm{~cm}$, respectivamente. As menores diferenças encontradas entre os tratamentos (solo descoberto e com grama) ocorreram nos meses de abril e dezembro de 2014 e entre fevereiro e maio de 2015. Este fato pode ser explicado em vista da incidência solar direta no solo sem cobertura, uma vez que o solo com cobertura permite menor aquecimento no solo. Resposta semelhante foi descrita por Sandanielo (1983), quando comparou solo sem cobertura, com cobertura morta e com relva de gramínea, concluindo que a cobertura atenuava as ondas térmicas, diminuindo os valores de temperatura.

Conforme dados presentes na Figura 1, observam-se os baixos valores de temperatura durante o período de maio a setembro/2014, estes vão aumentando nos meses de outubro/2014 a abril/2015, voltando a diminuir nos meses de maio a agosto/2015. Ou seja, a temperatura média mensal durante a estação chuvosa apresentou médias superiores às do período seco. Resultados semelhantes foram descritos por Novais (2011), que observou a mesma resposta ao estudar a dinâmica térmica do solo do Pantanal mato-grossense, onde verificou que os maiores valores de médias mensais foram registrados durante 0 período com alto índice de precipitação.

O aumento da temperatura do solo durante os meses que registram maior índice de precipitação ocorre devido ao aumento da umidade do solo e, consequentemente, da condutividade térmica, onde os espaços ocupados por ar são substituídos por água. A ausência de água no período seco dificulta o fluxo de calor no solo, dificultando a condução de calor das camadas superficiais para as mais profundas (Carneiro et al., 2014; Funari et al., 2017). Do mesmo 
modo, a presença de água no solo afeta o fluxo de calor no mesmo, ou seja, a existência de umidade no solo altera a amplitude da temperatura do solo por ocasião da evaporação (Cortez et al., 2015).

Observou-se que, no solo cultivado com grama, as temperaturas médias mensais nas camadas mais profundas permaneceram elevadas. Segundo Cademartori et al. (2010), o volume de água no solo atua diretamente na condutividade térmica; portanto, a variação da temperatura do solo é menor com o aumento do volume de água armazenada.

No solo descoberto, a variabilidade mensal da temperatura foi superior ao solo cultivado com grama, sendo que os meses de agosto, setembro, outubro/2014 e agosto/2015 apresentaram as maiores médias e a amplitude térmica entre as camadas. Ao observar a precipitação nos meses de novembro de 2014 a abril de 2015, verificou-se que a temperatura média mensal variou conforme a quantidade de chuva, sendo que, nos meses de novembro/2014, janeiro e março/2015, as médias foram maiores que as dos meses de dezembro/2014, fevereiro e abril/2015, onde o índice de precipitação foi superior.

No período de julho a setembro de 2014 e no mês de agosto de 2015, a temperatura na camada de $5 \mathrm{~cm}$ foi superior em relação às camadas de 10; 20 e $40 \mathrm{~cm}$, sendo que, em ambos os anos, o mês de agosto, cuja precipitação foi menor, apresentou maior variação entre as profundidades. Nos meses mais chuvosos, dezembro/2014, fevereiro e abril/2015, a situação inverteu-se, ou seja, a temperatura do solo aos $40 \mathrm{~cm}$ tornou-se superior às demais profundidades, devido à ocorrência de precipitação que tende a resfriar as camadas superiores do solo.

A temperatura do solo apresentou a mesma tendência da temperatura do ar, porém com oscilações mais atenuadas em resposta aos diferentes tratamentos e profundidades. Estudando a estimativa da temperatura do solo descoberto e com cobertura de palha seca, e verificando qual a correlação entre a temperatura do ar e a do solo, Belan et al. (2013) verificaram que a temperatura no perfil de um Latossolo Vermelho-Amarelo varia em função da profundidade e da condição de cobertura do solo. Neste mesmo estudo, os autores observaram que, em solos sem cobertura, a temperatura do mesmo demonstrou maiores amplitudes ao longo do dia em relação ao solo coberto, sendo que as amplitudes na temperatura do solo variaram entre as diferentes profundidades estudadas, resultado também encontrado neste estudo.

\section{Variabilidade máxima, média e mínima horária da temperatura do solo}

Observou-se temperatura máxima de $41,8^{\circ} \mathrm{C}$ aos $5 \mathrm{~cm}$, no tratamento com solo descoberto, e $32,2^{\circ} \mathrm{C}$ na mesma camada para o tratamento com grama. A presença da cobertura de grama no solo reduziu a temperatura máxima em $9,7^{\circ} \mathrm{C}$ na camada superficial (Figura 2A). Resultados semelhantes foram encontrados por Gasparim et al. (2005), ao analisarem o efeito da cobertura no solo, na temperatura de um
Latossolo Vermelho distroférrico, na região de Cascavel-PR, e observaram temperaturas superiores a $40^{\circ} \mathrm{C}$ em solo sem cobertura e $31^{\circ} \mathrm{C}$ em solo com cobertura. Deste modo, observa-se que, em diferentes regiões do Brasil, os valores de temperatura máxima do solo têm respostas semelhantes para o mesmo tipo de solo.

Pezzopane et al. (1996) verificaram redução de $9,5^{\circ} \mathrm{C}$ na temperatura máxima do solo com cobertura na superfície, e independentemente da região, do tipo de clima e solo e do uso de cobertura na superfície do solo, a amplitude térmica horária é reduzida pela diminuição da temperatura máxima do solo, aumentando o conteúdo de água no solo, evitando perdas de água devido à evaporação do solo ser menor (Knies, 2010).

Em trabalho realizado por Silva et al. (2006b), com objetivo de determinar o efeito de três sistemas de manejo na temperatura do solo, durante todo o ciclo do feijoeiro, em um Argissolo Vermelho distrófico arênico, em Santa Maria - RS, sob clima subtropical úmido, os autores puderam verificar que a temperatura máxima do solo, medida durante todo o ciclo do feijoeiro, foi de $43,7^{\circ} \mathrm{C}$, aos $2,5 \mathrm{~cm}$ de profundidade, no sistema de cultivo sem revolvimento do solo. No sistema de cultivo onde o solo foi revolvido, também foram verificadas altas temperaturas na profundidade de $2,5 \mathrm{~cm}$, com máxima de $42,2^{\circ} \mathrm{C}$. No plantio direto, a palha na superfície evitou que o solo se aquecesse na mesma proporção dos outros sistemas, em torno de $36^{\circ} \mathrm{C}$.

A temperatura máxima do solo com grama, nas profundidades de 5; 10; 20 e $40 \mathrm{~cm}$, manteve-se inferior à temperatura máxima do solo sem cobertura, diferença que diminuiu conforme o aumento da profundidade. Aos $40 \mathrm{~cm}$, a diferença de temperatura máxima entre os tratamentos foi de $3,1^{\circ} \mathrm{C}$. Na profundidade de $20 \mathrm{~cm}$, no tratamento com grama, a máxima foi de $29,7^{\circ} \mathrm{C}$ e ocorreu às $16 \mathrm{~h}$, e aos $40 \mathrm{~cm}$ foi de $29,4^{\circ} \mathrm{C}$ às $13 \mathrm{~h}$. Para o tratamento com solo descoberto, os valores máximos foram de $35,2^{\circ} \mathrm{C}$ às $16 \mathrm{~h}$ e $32,5^{\circ} \mathrm{C}$ às $11 \mathrm{~h}$, nas profundidades de 20 e $40 \mathrm{~cm}$, respectivamente (Figuras $2 \mathrm{~A}$ e $2 \mathrm{~B}$ ).

No solo mantido com grama, a temperatura média na profundidade de $5 \mathrm{~cm}$, das $11 \mathrm{~h}$ às $19 \mathrm{~h}$, foi de 2,6 a $5,7^{\circ} \mathrm{C}$ menor do que no solo descoberto (Figuras $2 \mathrm{C}$ e 2D). Resultados semelhantes foram encontrados por Knies (2010), que verificou um decréscimo de 3 a $4{ }^{\circ} \mathrm{C}$ aos $3 \mathrm{~cm}$ de profundidade, em solo cultivado com milho, em relação ao solo sem cobertura, na região de Santa Maria - RS.

Nas profundidades de 20 e $40 \mathrm{~cm}$, a temperatura média no solo descoberto foi superior à de solo com grama, enquanto no solo sem cobertura a temperatura, aos $20 \mathrm{~cm}$, variou de 27,1 a $29,2^{\circ} \mathrm{C}$; no solo com grama, as temperaturas médias mantiveram-se entre 26,2 e $26,7^{\circ} \mathrm{C}$. Aos $40 \mathrm{~cm}$, observou-se baixa variação, durante as horas do dia, em ambos os sítios de avaliação; no entanto, o solo com grama manteve temperaturas médias inferiores, entre 1,2 a 1,4 ${ }^{\circ} \mathrm{C}$, em relação às observadas no solo descoberto (Figuras $2 \mathrm{C}$ e 2D). 

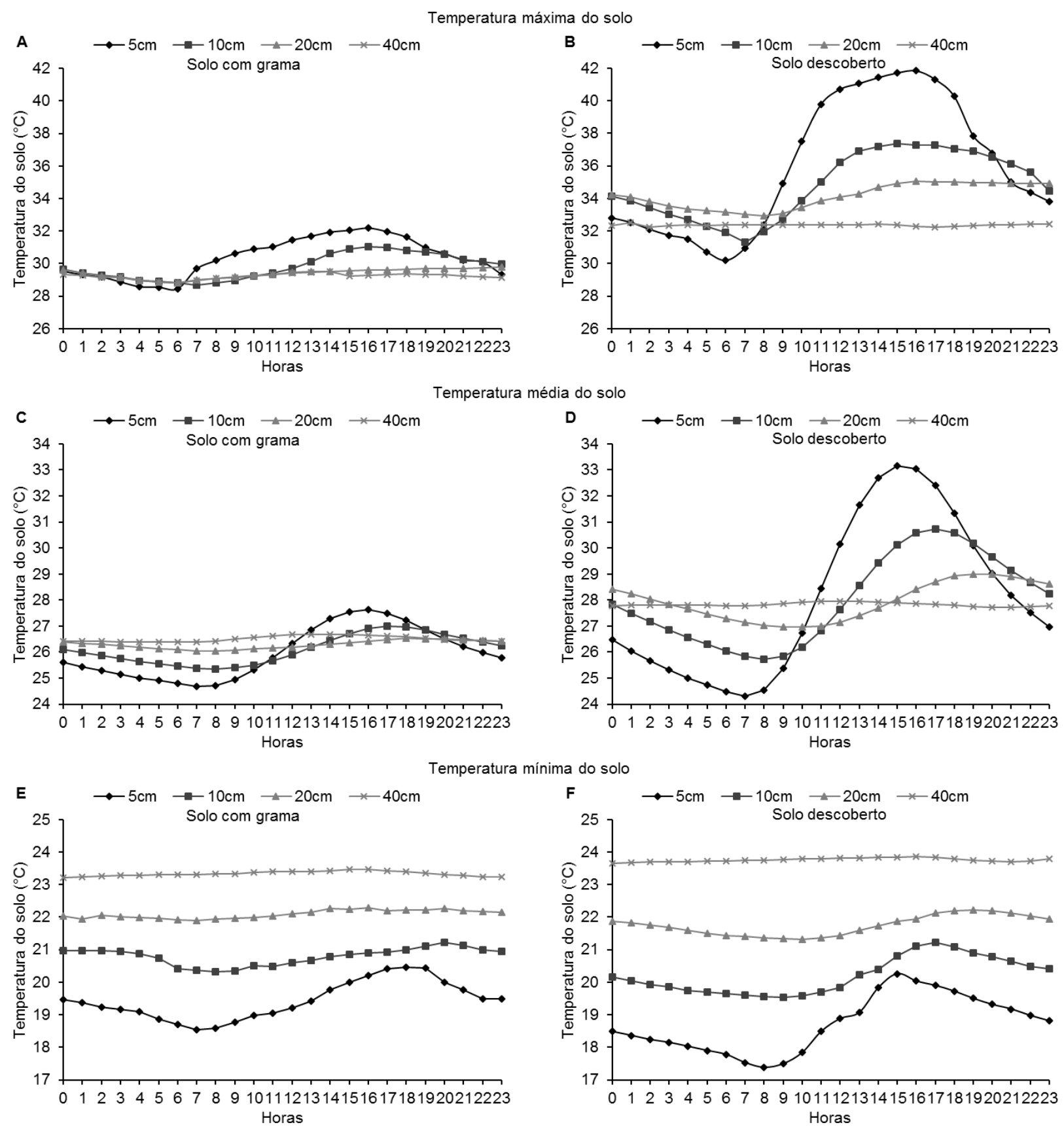

Figura 2 - Variabilidade horária das temperaturas máximas (A e B), médias (C e D) e mínimas (E e F) no tratamento com grama (A, $C$ e E) e com solo descoberto (B, D e F), nas profundidades de $5 ; 10 ; 20$ e $40 \mathrm{~cm}$. Time variability of the maximum temperatures $(A$ and $B)$, means $(C$ and $D)$ and minimum $(E$ and $F)$ in the treatment with grass $(A, C$ and $E)$ and with uncovered soil (B, $D$ and $F)$, at the depths of $5,10,20$ and $40 \mathrm{~cm}$.

A presença de plantas sobre o solo reduz a temperatura e a amplitude térmica, devido à reflexão e à absorção de energia solar incidente. Carneiro et al. (2013) ressaltam que a superfície do solo com presença de cobertura vegetal exerce função importante sobre a temperatura do solo, de maneira que a cobertura vegetal é responsável pela troca e pelo armazenamento de energia térmica nos ecossistemas terrestres. Coberturas vegetais presentes sobre o solo interceptam uma parte da radiação solar pelo dossel vegetativo; desta maneira, a área foliar existente da cultura ou da espécie vegetal diminui a disponibilidade de energia solar na superfície do solo, apresentando menor variação diária da temperatura do solo (Marques Filho et al., 2005; Casaroli et al., 2007).

A resposta das temperaturas máximas e médias, durante as horas do dia, no solo descoberto, mostrou-se semelhante nas camadas superficiais do solo, cujas temperaturas elevadas ocorreram das $11 \mathrm{~h}$ às $20 \mathrm{~h}$, e temperaturas mais baixas entre $21 \mathrm{~h}$ e $10 \mathrm{~h}$ 
(Figura 2). Segundo Silva (2006a), no solo sem cobertura, há maior aquecimento durante o dia e maior resfriamento durante a noite, sendo que durante o dia a radiação terrestre é maior e o fluxo de calor é mais intenso para o interior do solo, e no período da noite, o fluxo de calor é invertido, pois passa mais rápido do interior do solo para a superfície.

Através da análise horária da temperatura média, observou-se que a amplitude térmica no tratamento com solo descoberto foi de 9,0;5,1;2,1 e $0,3^{\circ} \mathrm{C}$, nas profundidades de $5 ; 10 ; 20$ e $40 \mathrm{~cm}$, respectivamente. No solo com grama, as amplitudes foram de $2,8^{\circ} \mathrm{C}(5 \mathrm{~cm}), 1,6^{\circ} \mathrm{C}(10 \mathrm{~cm}), 0,5^{\circ} \mathrm{C}(20 \mathrm{~cm})$ e $0,3^{\circ} \mathrm{C}(40 \mathrm{~cm})$ (Figuras $2 \mathrm{C}$ e 2D). Segundo Salton \& Mielniczuk (1995), o sistema de plantio com cobertura no solo proporciona menor temperatura máxima e menor amplitude térmica no solo do que no sistema de plantio sem cobertura. Os resultados indicam que, em profundidades maiores de $20 \mathrm{~cm}$, como de transição das variações térmicas, determina duas zonas geotérmicas: uma superior, caracterizada pelas grandes oscilações térmicas, e outra inferior, em que as temperaturas oscilam entre valores muito próximos (Gasparim et al., 2005).

As menores temperaturas mínimas horárias foram registradas aos $5 \mathrm{~cm}$ no solo descoberto, cujo valor registrado foi de $17,4^{\circ} \mathrm{C}$. No tratamento com grama, o menor valor foi de $18,5^{\circ} \mathrm{C}$ aos $5 \mathrm{~cm}$ de profundidade, seguido das camadas de 10; 20 e $40 \mathrm{~cm}$, que apresentaram resposta crescente de acordo com o aumento da profundidade do solo. Na camada de $40 \mathrm{~cm}$, a temperatura mínima variou entre 23,2 e $23,5^{\circ} \mathrm{C}$, no tratamento com grama, e para o solo descoberto a variação foi de 23,6 a $23,9^{\circ} \mathrm{C}$ (Figuras $2 \mathrm{E}$ e $2 \mathrm{~F}$ ). A presença da grama no solo provocou a redução da temperatura máxima e o aumento da temperatura mínima, ocasionando as menores amplitudes térmicas.

A amplitude térmica no solo com grama foi reduzindo conforme o aumento da profundidade, apresentando amplitude de 13,$7 ; 10,6 ; 7,8$ e $6,2^{\circ} \mathrm{C}$ aos 5 ; 10; 20 e $40 \mathrm{~cm}$, respectivamente. Os valores verificados no solo descoberto foram maiores, sendo que nas profundidades de $5 ; 10 ; 20$ e $40 \mathrm{~cm}$, a amplitude térmica foi de 24,$5 ; 18,7 ; 14,1$ e $8,9^{\circ} \mathrm{C}$, respectivamente. Resultados semelhantes foram descritos por Chabat (2010), em que as menores temperaturas mínimas do solo sem cobertura foram registadas aos 5 e $10 \mathrm{~cm}$ de profundidade, onde a amplitude térmica do solo sem cobertura foi de $25,2^{\circ} \mathrm{C}$, e de $16,5^{\circ} \mathrm{C}$ no solo com cobertura.

\section{Variabilidade horária da temperatura do solo du- rante as estações seca e chuvosa}

$\mathrm{Na}$ Figura 3, está representada a resposta média horária nas diferentes profundidades, nos dois tratamentos estudados, separados em estação seca do ano de 2014 (maio a setembro), estação chuvosa (outubro/2014 a abril/2015) e para a estação seca de 2015 (maio a agosto).
As observações no solo com grama, durante a estação seca, revelaram que as temperaturas aos 20 e $40 \mathrm{~cm}$ foram maiores do que aos $5 \mathrm{~cm}$, durante as últimas horas da noite até às primeiras horas da tarde (de $22 \mathrm{~h}$ até às $12 \mathrm{~h}$ ), onde se notou que a transferência de calor se realizou das camadas mais profundas às mais superficiais, e dessa forma o fluxo de calor no solo foi negativo. A camada de $5 \mathrm{~cm}$ teve as maiores temperaturas das $14 \mathrm{~h}$ às $19 \mathrm{~h}$, com máxima de $26,7^{\circ} \mathrm{C}$ às $16 \mathrm{~h}$ (Figura $3 \mathrm{~A}$ ). Segundo Cademartori et al. (2010), o saldo de radiação negativo provoca a redução da amplitude térmica do solo com maior volume de água, porém a temperatura deste é mais elevada, devido à absorção de radiação ao longo do dia e da maior condutividade térmica.

O solo descoberto, durante o período seco, apresentou variabilidade entre as camadas, na profundidade de $5 \mathrm{~cm}$, e os valores médios variaram de 33,1 a $23,7^{\circ} \mathrm{C}$, cuja amplitude térmica foi de $9,4^{\circ} \mathrm{C}$ (Figura 3B). Nas diferentes profundidades, a estação seca apresentou as maiores variações na temperatura média horária, cujas amplitudes foram de 9,4; 5,3; 2,1 e $0,3^{\circ} \mathrm{C}$ nas camadas de $5 ; 10 ; 20$ e $40 \mathrm{~cm}$, respectivamente. A presença da grama na superfície do solo reduziu a amplitude térmica, e aos 5; 10; 20 e $40 \mathrm{~cm}$ observaram-se valores de 3,$2 ; 1,8 ; 0,5$ e $0,3^{\circ} \mathrm{C}$, respectivamente (Figuras $3 \mathrm{~A}$ e $3 \mathrm{~B}$ ).

$\mathrm{Na}$ estação chuvosa, as temperaturas médias durante as horas dos dias foram superiores às da estação seca, sendo que a máxima, no solo com grama, foi de $29,3^{\circ} \mathrm{C}$ e ocorreu na profundidade de $5 \mathrm{~cm}$ as $14 \mathrm{~h}$, e a mínima foi de $26,6^{\circ} \mathrm{C}$, registrada às $7 \mathrm{~h}$ na mesma camada. Porém a amplitude térmica durante a estação chuvosa foi de $8,3^{\circ} \mathrm{C}(5 \mathrm{~cm}), 4,7^{\circ} \mathrm{C}(10 \mathrm{~cm})$, $1,9^{\circ} \mathrm{C}(20 \mathrm{~cm})$ e $0,3^{\circ} \mathrm{C}(40 \mathrm{~cm})$ no solo descoberto. No solo com grama, a amplitude térmica foi de 2,7; 1,$5 ; 0,4$ e $0,3^{\circ} \mathrm{C}$ aos $5 ; 10 ; 20$ e $40 \mathrm{~cm}$, respectivamente (Figura $3 \mathrm{C}$ ).

As variações de temperatura do solo entre a estação seca e a chuvosa, nos tratamentos estudados, podem ser justificadas pelo fato de que o armazenamento de água no solo com grama foi superior ao do solo sem cobertura. Outro fator que explica a resposta da temperatura entre os tratamentos estudados e os períodos seco e chuvoso deve-se, à maioria da radiação líquida (energia) que chega ao solo, é gasta no processo de aquecimento da água e da evaporação (fluxo de calor latente), sobrando pouca energia para o aquecimento do solo, enquanto no período seco, a radiação é quase toda consumida pelo fluxo de calor sensível (ar) e pelo fluxo de calor no solo, apresentando maiores temperaturas do solo (Pezzopane et al., 1996; Carneiro et al., 2013).

Na Figura 4, é possível verificar a distribuição dos valores entre a diferença da temperatura do solo e da temperatura do ar, para os períodos diurno $(7 \mathrm{~h}$ às $18 \mathrm{~h}$ ) e noturno ( $19 \mathrm{~h}$ às $6 \mathrm{~h}$ ), durante as estações chuvosa e seca, nos diferentes tratamentos e profundidades. Os valores encontrados demonstram que, durante a estação chuvosa no período diurno, a tempe- 
ratura do solo, tanto para o descoberto, quanto para o coberto com grama, teve maior variação em relação ao período noturno.

Observou-se que a maior variabilidade dos dados ocorre durante a estação seca, pois o solo coberto apresentou diferenças negativas, ou seja, a tem- peratura do solo é inferior à temperatura do ar durante o período analisado. Das $7 \mathrm{~h}$ às $18 \mathrm{~h}$, o solo descoberto apresentou diferenças positivas na profundidade de $5 \mathrm{~cm}$. Nas profundidades de 10; 20 e $40 \mathrm{~cm}$, observaram-se diferenças positivas e negativas.
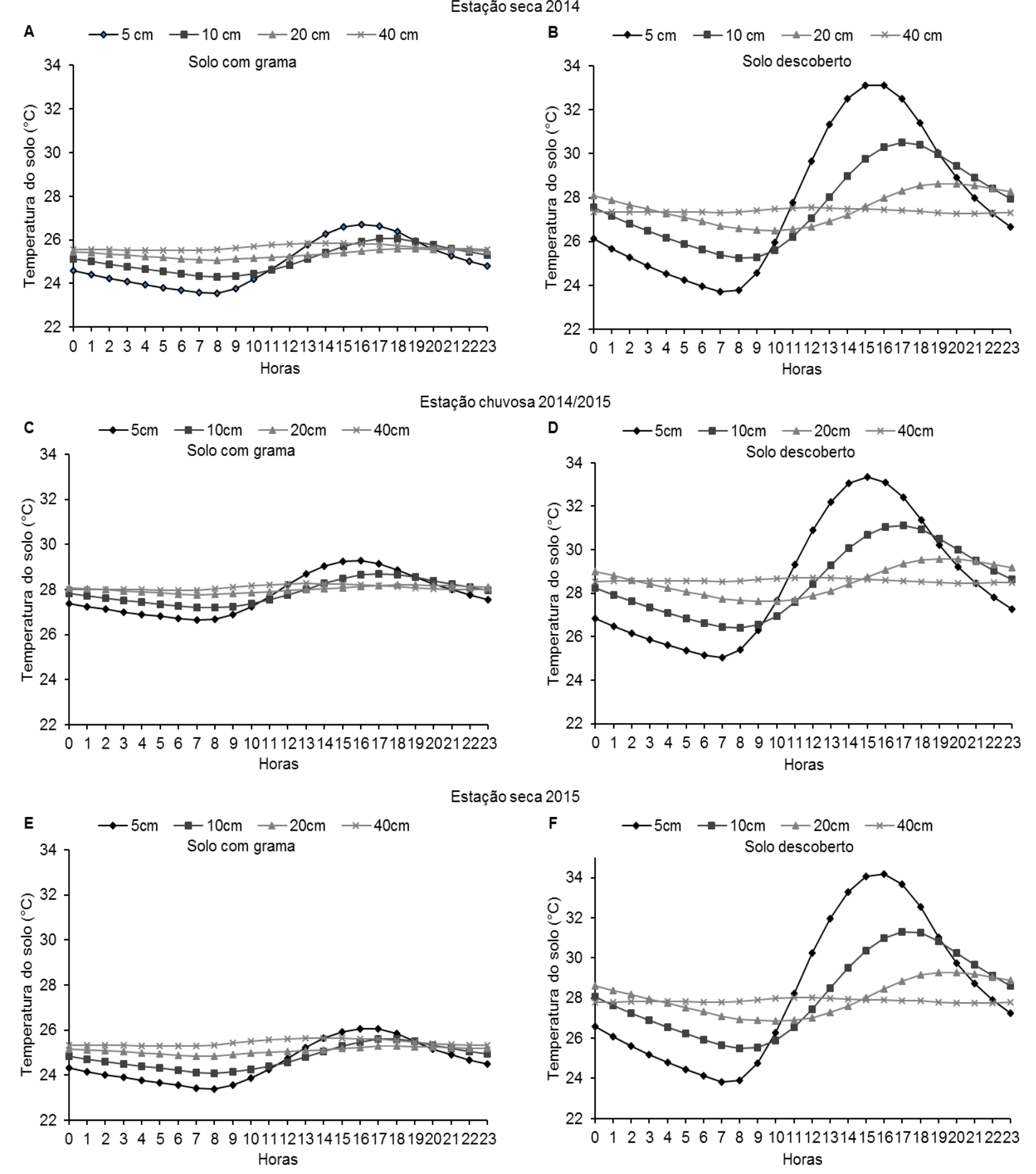

Figura 3 - Temperaturas médias horárias do período seco (maio a setembro/2014) (A e B), período chuvoso (outubro/2014 a abril/2015) (C e D) e na estação seca de 2015 (maio a agosto) (E e F), nos tratamentos solo com grama (A, C e E) e solo descoberto (B, D e F), nas profundidades de 5; 10; 20 e $40 \mathrm{~cm}$. Average hourly temperatures of the dry period (May to September / 2014) (A and B), rainy season (October / 2014 to April / 2015) $(C$ and $D)$ and in the dry season of 2015 (May to August) ( $E$ and $F)$, in grass covered soil treatments $(A, C$ and $E$ ) and uncovered soil (B, $D$ and $F)$ at depths of $5,10,20$ and $40 \mathrm{~cm}$. 


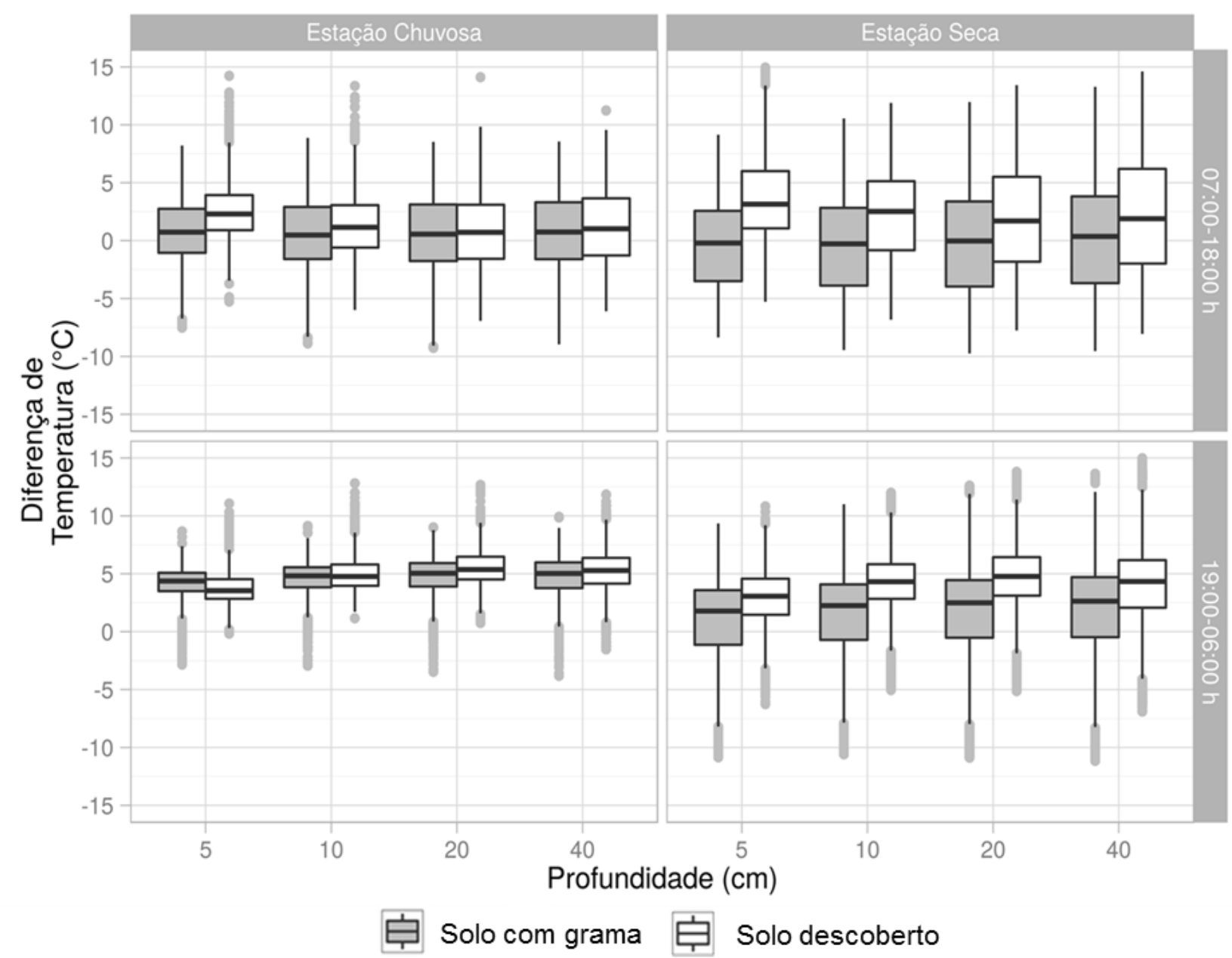

Figura 4 - Diferença entre a temperatura média horária do solo e do ar durante os períodos diurno e noturno, para a estação seca de 2014 (maio a setembro) e para estação chuvosa (outubro/2014 a abril/2015), nos tratamentos do solo coberto com grama e do solo descoberto, nas diferentes profundidades. Difference between the average hourly soil and air temperature during the day and night periods, for the dry season of 2014 (May to September) and for the rainy season (October/2014 to April/2015) in the soil treatments covered with grass and uncovered soil at different depths.

A temperatura do ar foi superior durante a estação seca, provocando maiores diferenças entre as temperaturas do solo e do ar, em ambos os tratamentos e profundidades. Das $7 \mathrm{~h}$ às $18 \mathrm{~h}$ do dia, observouse a maior variabilidade dos dados, uma vez que durante o dia a média de temperatura do ar foi superior à média que ocorre durante a noite e as primeiras horas da manhã. Ressalta-se que, no tratamento de solo descoberto, as menores diferenças ocorreram na profundidade de $5 \mathrm{~cm}$, evidenciando que as camadas superficiais sofrem maior influência da temperatura do ar.

$\mathrm{Na}$ estação chuvosa, a variabilidade dos dados foi inferior à ocorrida no período seco. Pode-se verificar que houve pouca variação entre os tratamentos e as profundidades. Das $19 \mathrm{~h}$ até às $6 \mathrm{~h}$, as diferenças entre a temperatura do solo e do ar permaneceram positivas em ambos os tratamentos $\mathrm{e}$ profundidades. No período seco, o solo com grama apresenta menores valores de temperatura do solo, em função de apresentar maiores quantidades de água no solo, ao contrário da estação chuvosa da região, onde as chuvas são frequentes e a variabilidade da temperatura do solo é menor (Figura 4). Coelho et al. (2013) relatam que as variações entre a temperatura do solo descoberto, daquele mantido com cobertura vegetal, estar relacionadas com o conteúdo de água no solo, sendo maior a diferença quanto mais umidade o solo retém.

A análise da variabilidade horária no tratamento com grama, durante as estações do ano, demonstrou que, no inverno, as temperaturas, em ambas as profundidades, concentram-se entre 23,1 e $26,5^{\circ} \mathrm{C}$ na camada superficial do solo. A amplitude térmica neste período foi de 3,$5 ; 2,0 ; 0,6$ e $0,4^{\circ} \mathrm{C}$ para as camadas de 5; 10; 20 e $40 \mathrm{~cm}$, respectivamente (Figura 5). 

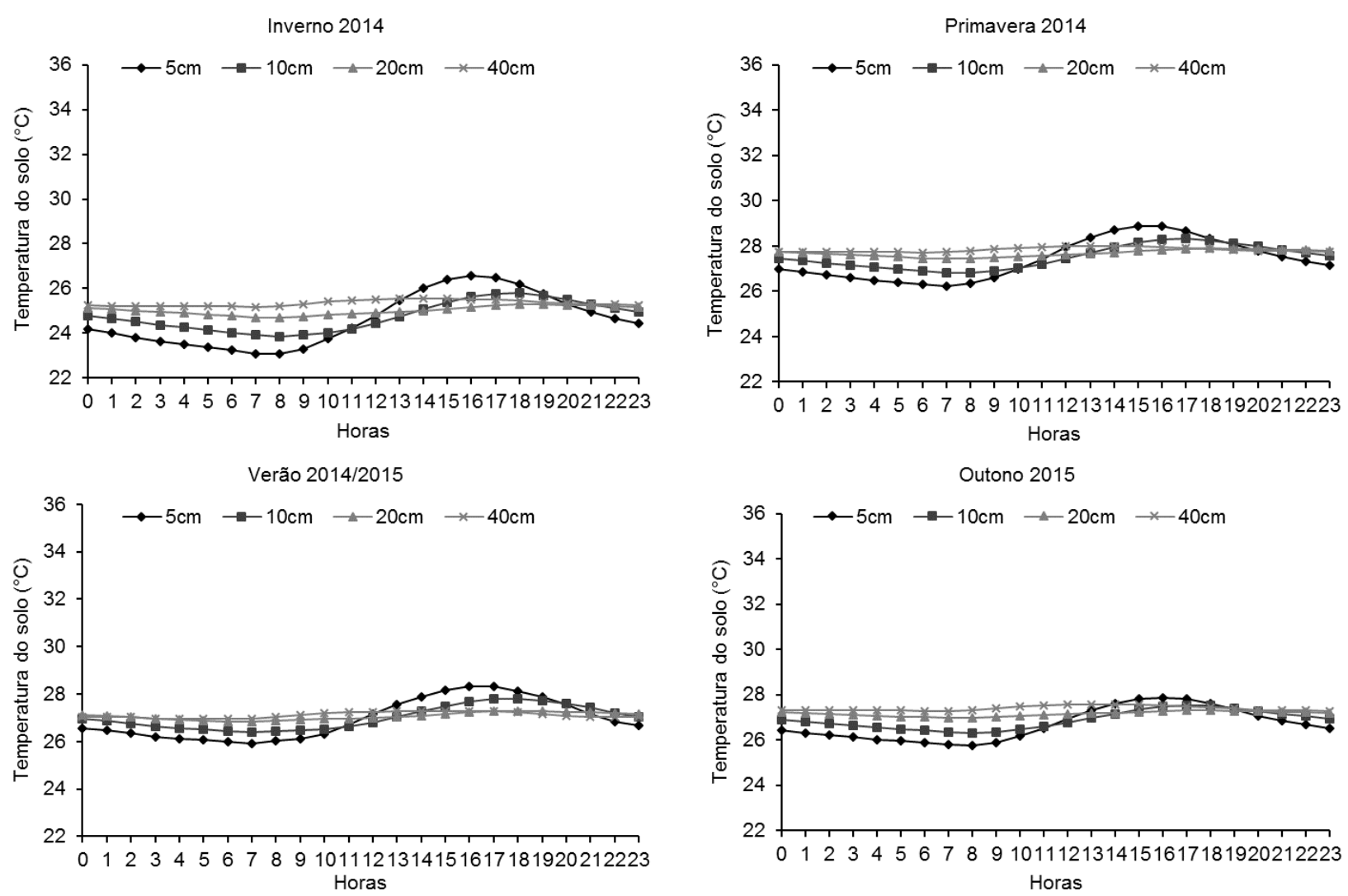

Figura 5 - Variabilidade média horária da temperatura do solo no tratamento de solo coberto com grama, durante as estações de inverno, primavera, verão e outono, nas profundidades de 5; 10; 20 e $40 \mathrm{~cm}$. Mean hourly variability of soil temperature in the treatment of grass covered soil, during the winter, spring, summer and fall seasons, at depths of 5, 10, 20 and $40 \mathrm{~cm}$.

Comparando-se a temperatura do solo durante a estação de verão com as ocorridas durante o inverno, verificou-se diferença de $2,1^{\circ} \mathrm{C}$ na temperatura média no solo, sendo que durante o verão esta foi de $27,0^{\circ} \mathrm{C}$ e durante o inverno de $24,9^{\circ} \mathrm{C}$. Apesar das altas temperaturas durante o verão, as amplitudes térmicas apresentaram-se inferiores às do período de inverno, sendo estas de 2,$4 ; 1,4 ; 0,5$ e $0,3^{\circ} \mathrm{C}$, nas profundidades de $5 ; 10 ; 20$ e $40 \mathrm{~cm}$, respectivamente. A região Centro-Oeste é caracterizada por ter inverno frio e seco e verão quente e chuvoso. Em geral, a precipitação média anual fica entre 1.200 e 1.800 mm e apresenta uma grande estacionalidade, concentrando-se nos meses de primavera e verão (outubro a março), a estação chuvosa. No período de maio a setembro, os índices pluviométricos mensais reduzem-se bastante, podendo chegar a zero (Marcuzzo et al., 2012). Portanto, pode-se perceber, através da análise dos gráficos, que a precipitação pluviométrica é um dos fatores determinantes da variabilidade da temperatura do solo e da amplitude térmica, e que durante a primavera e o verão observaram-se redução na amplitude térmica $e$ aumento na temperatura média durante as horas do dia.

No solo descoberto, as temperaturas registradas foram superiores às do solo com grama (Figura 6). No inverno, estas variaram de 23,8 a $34,2^{\circ} \mathrm{C}$; no ve- rão, permaneceram entre 24,7 e $33,7^{\circ} \mathrm{C}$; na primavera, de 25,4 a $33,8^{\circ} \mathrm{C}$ e, durante o outono, de 23,9 a $31,4^{\circ} \mathrm{C}$. Verificou-se que a amplitude térmica durante as estações estudadas foi de 10,4; 5,8; $2,4 \mathrm{e}$ $0,3^{\circ} \mathrm{C}$, durante $\mathrm{o}$ inverno, para as camadas de $5 ; 10$; 20 e $40 \mathrm{~cm}$, respectivamente. No verão, apresentaram redução de 1,$3 ; 0,6 ; 0,1$ e $0,1^{\circ} \mathrm{C}$ nas profundidades de 5; 10; 20 e $40 \mathrm{~cm}$, respectivamente.

As menores amplitudes térmicas foram registradas durante o outono, sendo que os valores foram de $7,5(5 \mathrm{~cm}) ; 4,3(10 \mathrm{~cm}) ; 1,7(20 \mathrm{~cm})$ e $0,3^{\circ} \mathrm{C}$ $(40 \mathrm{~cm})$. Aos $5 \mathrm{~cm}$ de profundidade, em ambas as estações, as temperaturas $e$ as amplitudes apresentaram-se superiores às das demais camadas. A temperatura média mensal em solo descoberto é maior em profundidades menores na estação do verão, sendo que quando se aproxima do inverno isso acaba invertendo-se, ou seja, a temperatura torna-se maior em maiores profundidades do solo (Gasparim et al., 2005).

Verificou-se em ambas as figuras (Figuras $5 \mathrm{e}$ 6) que entre as $11 \mathrm{~h}$ e as $20 \mathrm{~h}$, em todas as estações do ano, as temperaturas do solo permaneceram altas e vão reduzindo-se, a partir das $21 \mathrm{~h}$, sendo os menores valores registrados entre as $6 \mathrm{~h}$ e as $8 \mathrm{~h}$ da manhã. Sendo assim, a transferência de calor de uma camada para a outra é negativa nas primeiras horas do dia e nas últimas horas da noite, e positiva durante a tarde e as primeiras horas da noite. 

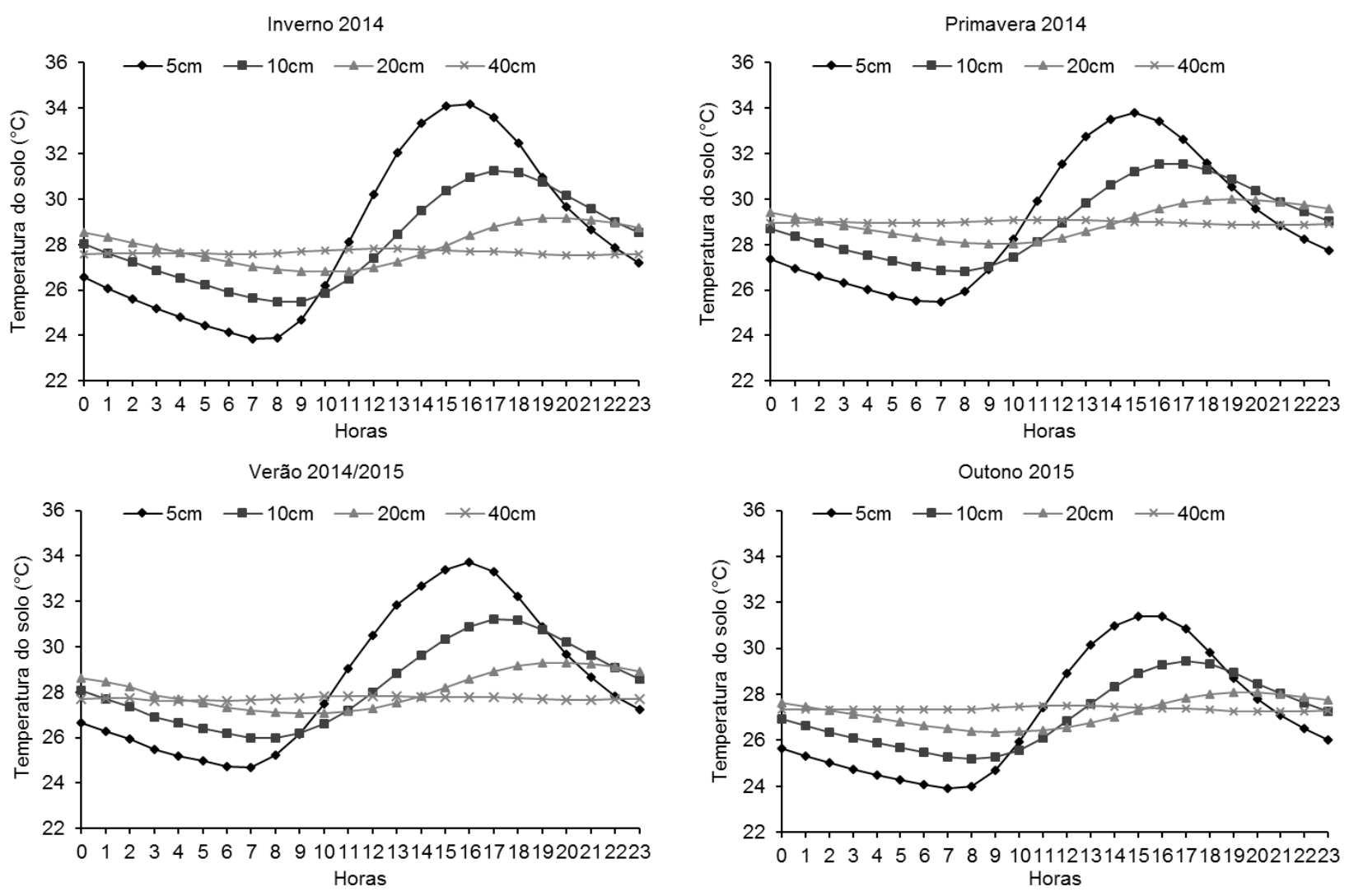

Figura 6 - Variabilidade média horária da temperatura do solo no tratamento de solo descoberto, durante as estações de inverno, primavera, verão e outono, nas profundidades de 5; 10; 20 e $40 \mathrm{~cm}$. Mean hourly variability of soil temperature in the treatment of uncovered soil, during the winter, spring, summer and fall seasons, at depths of 5, 10, 20 and $40 \mathrm{~cm}$.

\section{Conclusões}

As médias horárias de temperatura para o Latossolo Vermelho distroférrico muito argiloso na região de Tangará da Serra - MT, sofrem influência pela cobertura vegetal de grama. Para o solo com grama nas profundidades de 5; 10; 20 e $40 \mathrm{~cm}$, as médias de temperatura do solo foram de 26,0; 26,1 ; 26,3 e $26,5^{\circ} \mathrm{C}$, respectivamente. $\mathrm{O}$ solo descoberto apresentou médias de temperatura do solo de 28,1 ; 28,$0 ; 27,9$ e $27,8^{\circ} \mathrm{C}$ nas profundidades de $5 ; 10 ; 20$ e $40 \mathrm{~cm}$, respectivamente.

Nas profundidades de $5 ; 10 ; 20$ e $40 \mathrm{~cm}$, o solo com grama apresentou menor variação diurna nas temperaturas do solo quando comparado ao solo descoberto.

Durante os meses de abril de 2014 e agosto de 2015, as médias horárias do solo com grama apresentaram-se maiores, porém as oscilações durante as horas do dia foram menores, quando comparadas às ocorridas no solo descoberto, onde as variações durante as horas do dia foram maiores, e as médias horárias, menores.

As maiores amplitudes térmicas ocorreram durante o mês seco em ambos os tratamentos, sendo que no solo descoberto a amplitude térmica aos $5 \mathrm{~cm}$ de profundidade foi de $11,3^{\circ} \mathrm{C}$.

A precipitação foi um dos fatores que influenciaram as oscilações ocorridas na temperatura do solo, entre os meses de novembro de 2014 e maio de 2015, onde ocorreu alto índice de chuvas, e as médias horárias sofreram menores variações.

Durante as estações de primavera e verão, as médias horárias de temperatura do solo foram superiores à estação de inverno, porém as oscilações durante as horas do dia foram menores, tanto no solo com grama quanto no solo descoberto.

\section{Agradecimentos}

Ao auxílio financeiro do projeto de pesquisa Aplicação e transferência de tecnologias na otimização de sistemas agrícolas sustentáveis, Processo CNPq 564112/2010-0, edital $\mathrm{MCT} / \mathrm{CNPq} / \mathrm{FNDCT} / \mathrm{FAPs} / \mathrm{MEC} / \mathrm{CAPES} / \mathrm{PRO}-\mathrm{CEN}$ TRO-OESTE № 031/2010.

À Coordenação de Aperfeiçoamento de Pessoal de Nível Superior (CAPES) pela concessão de bolsa de estudos.

\section{Referências}

Belan LL, Xavier TMT, Torres H, Toledo JV, Pezzopane JEM (2013) Dinâmica entre temperaturas do ar e do solo sob duas condições de cobertura. Rev Acad: Cienc Agrar Ambient 11(1):147-154. doi: 10.7213/academica.10.S01.AO17. 
Bergamaschi H, Matzenauer R (2014) O milho e o clima. Porto Alegre: Emater/RS-Ascar. 85p.

Bezerra AC, Montenegro AAA, Pandorfi H, Silva JRL, Andrade CWL, Silva WP (2016) Variabilidade espaço temporal da temperatura do solo sob diferentes coberturas no semiárido pernambucano. Water Resources and Irrigation Management 5(2):75-85.

Cademartori RTO, Buriol GA, Righes AA (2010) Influência de diferentes coberturas na temperatura do solo. Disciplinarum Scientia. Série Ciências Naturais e Tecnológicas 11(1):149-157.

Carneiro RG, Moura MAL, Silva VPR, Silva Junior, RS, Andrade, AMD, Santos, AB (2014) Variabilidade da temperatura do solo em função da liteira em fragmento remanescente de Mata Atlântica. Revista Brasileira de Engenharia Agrícola e Ambiental, 18(1):99-108. doi: 10.1590/S1415-43662014000100013.

Carneiro RG, Moura MAL, Andrade, AMD (2013) Variação da temperatura do solo em um fragmento de mata atlântica em Coruripe-AL - um estudo de caso. Caminhos de Geografia, 14(46):139-149.

Casaroli D, Fagan EB, Simon J, Medeiros SP, Manfron PA, Neto DD, Van Lier QJ, Müller L, Martin TN (2007) Radiação solar e aspectos fisiológicos na cultura da soja uma revisão. Revista da FZVA, 14(2):102-120.

Chabat MM (2010) Influência dos resíduos vegetais na superfície do solo na dinâmica de evaporação da água e temperatura do solo. UFSM. (Dissertação de Mestrado em Ciência do Solo).

Coelho MEH, Freitas FCL, Cunha JLXL, Silva KS, Grangeiro LC, Oliveira JB (2013). Coberturas do solo sobre a amplitude térmica e a produtividade de pimentão. Planta Daninha 31(2):369-378. doi: 10.1590/S0100-83582013000200014.

Cortez JW, Nagahama HJ, Olszevski N, Patrocinio Filho AP, Souza EB (2015) Umidade e temperatura de argissolo amarelo em sistemas de preparo e estádios de desenvolvimento do milho. Engenharia Agrícola, 35(4):699-710. doi: 10.1590/1809-4430Eng.Agric.v35n4p699-710/2015.

Dalchiavon FC, Dallacort $R$, Inoue MH, Santi A, Nied AH, Martins JA, Coletti AJ (2010) Características agronômicas das sementes e dos frutos de pinhão-manso no município de Tangará da Serra, MT. Revista de Ciências Agro-ambientais 8(1):95-101.

Dallacort R, Martins JA, Inoue MH, Freitas PSL, Coletti AJ (2011) Distribuição das chuvas no município de Tangará da Serra, médio norte do Estado de Mato Grosso, Brasil. Acta Scientiarum. Agronomy 33(2):193200. doi: 10.4025/actasciagron.v33i2.5838.
Dallacort R, Moreira PSP, Inoue MH, Silva DJ, CarvaIho IF, Santos C (2010) Wind speed and direction characterization in Tangará da Serra, Mato Grosso State, Brazil. Revista Brasileira de Meteorologia 25(3):359364. doi: 10.1590/S0102-77862010000300007.

Dalmago GA, Bergamaschi H, Krüger CAMB, Bergonci JI, Comiran F, Heckler BMM (2010) Soil surface water evaporation under no-tillage and conventional tillage systems. Pesquisa Agropecuária Brasileira 45(8):780790. doi: 10.1590/S0100-204X2010000800002.

Embrapa (2013) Sistema brasileiro de classificação de solos. 3.ed. Brasília: Embrapa Informação Tecnológica. $353 p$.

Funari, FL, Pereira Filho, AJ (2017) Estimativa do fluxo de calor no solo a partir da temperatura do solo em São Paulo, SP. Revista do Instituto Geológico 38(1):49-57. doi: 10.5935/0100-929X.20170004.

Gasparim E, Ricieri RP, Silva SL, Dallacort R, Gnoatto E (2005) Temperatura no perfil do solo utilizando duas densidades de cobertura e solo nu. Acta Scientiarum. Agronomy 27(1):107-115. doi: 10.4025/actasciagron.v27i1.2127.

Hillel D (2004) Introduction to environmental soil physics. San Diego Elsevier/Acad. Press. 494 p.

Knies AE (2010) Temperatura de um solo franco arenoso cultivado com milho. UFSM (Dissertação de Mestrado em Ciência do Solo).

Lima JSS, Silva SA, Silva JM (2013) Variabilidade espacial de atributos químicos de um Latossolo Vermelho-Amarelo cultivado sob plantio direto. Revista Ciência Agronômica 44(1):16-23.

Marcuzzo FFN, Cardoso MRD, Faria TG (2012) Chuvas no Cerrado da região Centro-oeste do Brasil. Ateliê Geográfico 6(2):112-130. doi: 10.5216/ag.v6i2.15234.

Marques Filho AO, Dallarosa RG, Pachêco VB (2005) Radiação solar e distribuição vertical de área foliar em floresta - reserva biológica do cuieiras - ZF2, Manaus. Acta Amazônica, 35(4):427-436. doi: 10.1590/S004459672005000400007.

Matteucci MB, Lobato EJV (2004) Estudo do regime térmico em Latossolo vermelho escuro Distrófico em Goiânia, GO. Pesquisa Agropecuária Tropical 34(3):161-166.

Menezes DM, Pinto MM, Vivaldi LJ (1973) Estudo da temperatura do solo com e sem cobertura a diversas profundidades. Pesquisa Agropecuária Brasileira 8(6)39-51. 
Novais JWZ (2011) Dinâmica geotérmica do solo de uma floresta de cambarás no pantanal mato-grossense. UFMT. (Dissertação de Mestrado em Física Ambiental).

Oliveira ML, Ruiz HA, Costa LM, Schaefer CEGR (2005) Flutuações de temperatura e umidade do solo em resposta a cobertura vegetal. Revista Brasileira de Engenharia Agrícola e Ambiental 9(4):535-539. doi: 10.1590/S1415-43662005000400015.

Pezzopane JEM, Cunha GM, Arnsholz E, Costalonga Júnior M (1996) Temperatura do solo em função da cobertura morta por palha de café. Revista Brasileira de Agrometeorologia 4(2):7-10.

R Development Core Team (2017) R: A language and environment for statistical computing. Disponível em: <http://www.R-project.org/>. Acesso em: 03 dez. 2017.

Resende FV, Souza LS, Oliveira PSR, Gualberto R (2005) Uso de cobertura morta vegetal no controle da umidade e temperatura do solo, na incidência de plantas invasoras e na produção da cenoura em cultivo de verão. Ciência e Agrotecnologia 29(1):100-105. doi: 10.1590/S1413-70542005000100012.

Ribas GG, Streck NA, Silva SD, Rocha TSM, Langner JA (2015) Temperatura do solo afetada pela irrigação e por diferentes coberturas. Eng. Agríc. 35(5):817-828. doi: $828 / 2015$.
Salton JC, Mielniczuk J (1995) Relações entre sistemas de preparo, temperatura e umidade de um Podzólico Vermelho Escuro de Eldorado do Sul (RS). Revista Brasileira de Ciência do Solo 19(2):313-319.

Sandanielo A (1983) Estudo do ciclo diário do regime térmico do solo de Viçosa MG, sob três condições de cobertura. Viçosa: UFV. 79p.

SEPLAN-MT - Secretaria de Estado de Planejamento e Coordenação Geral (2003) Zoneamento Sócio Econômico Ecológico do Estado de Mato Grosso - 2002. Disponível em <http://www.seplan.mt.gov.br//3704951-zsee?ciclo=cv_gestao_inf $>$. Acesso em 01 abr. 2019.

Silva FAM, Pinto HS, Scopel E, Corbeels M, Affholder F (2006a) Dinâmica da água nas palhadas de milho, milheto e soja. Pesquisa Agropecuária Brasileira 41(5):717-724. doi: 10.1590/S0100204X2006000500001.

Silva VR, Reichert JM, Reinert DJ (2006b) Variação na temperatura do solo em três sistemas de manejo na cultura do feijão. Revista Brasileira Ciência do Solo 30(3):391-300. doi: 10.1590/S010006832006000300001.

Silveira APD, Freitas SS (2007) Microbiota do solo e qualidade ambiental. Campinas: IAC. 312p. 